\title{
Novos táxons em Acanthocinini sul-americanos (Coleoptera, Cerambycidae)
}

\author{
Marcela L. Monné1,2 \& Miguel A. Monné ${ }^{1,2}$
}

${ }^{1}$ Museu Nacional, Universidade Federal do Rio de Janeiro, Quinta da Boa Vista, São Cristóvão, 20940-040 Rio de Janeiro-RJ, Brasil.
${ }^{2}$ Bolsista do CNPq.

\begin{abstract}
New taxa in South American Acanthocinini (Coleoptera, Cerambycidae). The following new taxa are described and figured: Trichonyssodrys nessimiani sp. nov. from Brazil (Bahia to Santa Catarina), Amniscites tavakiliani sp. nov. from French Guiana and A. amboroensis sp. nov. from Bolivia (Cochabamba and Santa Cruz); Trichonius inusitatus sp. nov. and Lophopoenopsis itatiaiensis sp. nov. from Brazil (Rio de Janeiro) and Luteolepturges gen. nov., type species L. galbus sp. nov., from Brazil (Amazonas, Rondônia), Peru and Ecuador.
\end{abstract}

KEYWORDS. Lamiinae; new genus; new species; taxonomy.

RESUMO. Novos táxons em Acanthocinini sul-americanos (Coleoptera, Cerambycidae). São descritos e figurados os novos táxons: Trichonyssodrys nessimiani sp. nov. do Brasil (Bahia a Santa Catarina), Amniscites tavakiliani sp. nov. da Guiana Francesa and $A$. amboroensis sp. nov. da Bolívia (Cochabamba e Santa Cruz); Trichonius inusitatus sp. nov. e Lophopoenopsis itatiaiensis sp. nov. do Brasil (Rio de Janeiro) e Luteolepturges gen. nov., espécie tipo L. galbus sp. nov., do Brasil (Amazonas, Rondônia), Peru e Equador.

PALAVRAS-CHAVE. Lamiinae; novo gênero; novas espécies; taxonomia.

Prosseguindo o estudo dos Acanthocinini neotropicais, descrevemos diversos táxons inéditos, com base em material das instituições mencionadas a seguir: ACMT, American Coleoptera Museum, San Antonio, Texas, Estados Unidos; MNHM, Muséum National d'Histoire Naturelle, Paris, França, MNKM, Museo de Historia Natural Noel Kempff Mercado, Santa Cruz, Bolívia; MNRJ, Museu Nacional, Universidade Federal do Rio de Janeiro, Rio de Janeiro, Brasil; MZSP, Museu de Zoologia, Universidade de São Paulo, São Paulo, Brasil.

\section{Trichonyssodrys Gilmour, 1957}

Trichonyssodrys Gilmour, 1957: 31; Delfino, 1981: 255 (rev.); Monné, 2005: 140 (cat.).

Espécie-tipo: Trichonyssodrys maculatus Gilmour, 1957 (por designação original).

Junto aos gêneros Oxathres Bates, Sciadosoma Melzer, 1934, Pentheochaetes Melzer, 1932, Paraprobatius Breuning, 1955 e Sporetus Bates, 1864 compartilha os caracteres: lobos superiores dos olhos tão distantes entre si quanto uma a duas vezes a largura de um lobo; élitros com cerdas, sem carenas e sem crista centro-basal; protórax com tubérculos laterais, pronoto sem tubérculos; processo mesosternal igual à um quinto a metade da largura de uma mesocoxa e primeiro metatarsômero menor ou igual ao comprimento dos dois seguintes em conjunto.

Trichonyssodrys: separa-se de Oxathres e Sciadosoma pelo protórax com os lados subparalelos anterior e posteriormente aos tubérculos; de Pentheochaetes e Paraprobatius, pelo pro- cesso mesosternal com, pelo menos, um terço da largura de uma mesocoxa e distingue-se de Sporetus pelos tubérculos laterais do protórax cônicos e com extremidade aguçada. Em Oxathres e Sciadosoma o protórax é lateralmente arredondado e o tubérculo o prolongamento da respectiva curvatura. Em Pentheochaetes e Paraprobatius o processo mesosternal mede menos de um terço da largura de uma mesocoxa, por último em Sporetus o tubérculo lateral geralmente é reduzido a uma bossa mediana.

Chave para espécies de Trichonyssodrys, adaptada de Delfino (1981)

1. Cerdas elitrais muito escassas, restritas ao quarto basal; pronoto uniformemente revestido de pubescência acinzentada, às vezes com máculas laterais difusas castanhoescuras. Brasil (Bahia a Santa Catarina), Paraguai (Figs. $1,2)$ T. nessimiani sp. nov.

1 '. Cerdas elitrais abundantes, distribuídas em toda superfície; pronoto com duas cores de pubescência 2

2. Pubescência predominante amarelo-dourada. Venezuela. (Fig. 3) T. aureopilosus Monné, 1990

2'. Pubescência predominante castanho-escura, com máculas cinzento-esbranquiçadas 3

3. Superfície revestida de pubescência castanho-escura com pequenos pelos escamiformes esverdeados ou púrpura, dependendo do ângulo de incidência da luz; o ápice de escapo ultrapassa a margem posterior do protórax; antenômeros III-XI sem anéis de pubescência cinzentoesbranquiçada na metade anterior (Fig. 4) Brasil (Goiás, 
Minas Gerais a Santa Catarina), Argentina (Misiones) ..

T. maculatus Gilmour, 1957

3'. A superfície recoberta de pubescência castanho-escura sem pelos escamiformes; o ápice do escapo não atinge a margem posterior do protórax; antenômeros III-XI com anéis de pubescência cinzento-esbranquiçados

.. 4

4. Tegumento predominante castanho-avermelhado; metade basal dos élitros sem faixa castanho-escura. (Fig. 6) Brasil (São Paulo, Goiás) ................... T. cinctus Delfino, 1981

4'. Tegumento de maneira geral preto; metade basal dos élitros com faixa castanho escura. (Fig. 5) Brasil (Bahia, Minas Gerais) T. melasmus Delfino, 1981

\section{Trichonyssodrys nessimiani sp. nov.}

(Figs. 1, 2)

Etimologia. O epiteto é uma homenagem ao Professor Jorge Luiz Nessimian, por sua amizade e por seu valioso aporte ao conhecimento da entomologia.

Macho. Tegumento castanho-escuro. Pubescência predominante cinzento-esbranquiçada recobre o protórax, parte dos élitros (entremeada com pubescência castanho escura), face ventral e pernas. Pubescência castanho-escura disposta em faixas estreitas longitudinais no terço basal e na metade distal dos élitros. As antenas alcançam as extremidades dos élitros na extremidade distal do antenômero $\mathrm{V}$; escapo com fileira densa de cerdas curtas na face ventral. Tubérculo lateral do protórax no terço posterior, com ponta aguçada; pontuação do pronoto restrita à fileira junto da margem posterior. Processo prosternal com cerca de um quarto da largura de uma cavidade procoxal; processo mesosternal aproximadamente um terço de uma cavidade mesocoxal.

Élitros com cerdas muito escassas restritas ao quarto basal. Extremidades obliquamente truncadas, ângulos obtusos. Pontuação fina, moderadamente esparsa na metade basal. Último urotergito arredondado na extremidade distal; último urosternito truncado no ápice. Primeiro metarsômero aproximadamente igual aos dois seguintes em conjunto.

Fêmea. As antenas atingem as extremidades dos élitros aproximadamente no meio do antenômero VI. Último urotergito arredondado no ápice; último urosternito emarginado.

Dimensões, em mm, respectivamente macho/fêmea: Comprimento total, 6,1-9,4/8,7-9,7; comprimento do protórax, 1,0-1,5/1,3-1,6; comprimento dos élitros, 4,5-6,8/ 6,1-6,3; maior largura do protórax, 1,5-2,4/2,3-2,5; largura umeral, 2,0-3,5/3,0-3,1.

Material tipo. Holótipo macho, BRASIL, Paraná: Santa Mariana, 4.XI.1957, H. Zellibor col. (MNRJ). Parátipos: Bahia: Mun. Encruzilhada (Estrada Rio-Bahia, km 965, Motel da Divisa, 960 m), macho, XI.1972, Seabra \& Roppa col., mesmos dados, macho, XII.1972, 2 machos, XI.1974. Itamaraju, macho, X.1985, Roppa \& Becker col. Minas Gerais: Teofilo Otoni, macho, fêmea, XI.1972, S. P. Nascimento col. Espírito Santo: Mun. Barra do São Francisco, Córrego do Ita, macho, fêmea, X.1954, W. Zikán col. mesma localidade, macho, XI.1956, W. Grossmann col., macho, XI.1957, A. Almeida col. Linhares, fêmea, XI.1968, A. Maller col., fêmea, X.1970, B. Silva col., fêmea, IX.1972, P. C. Elias col., fêmea, XI.1972, P.
C. Elias col. (Parque Sooretama), macho, XI.1962, F. M. Oliveira col., mesma localidade e coletor, macho, X.1963. Conceição da Barra (Pedro Canario), fêmea, XI.1976, E. dos Santos col. Rio de Janeiro: Rio de Janeiro (Corcovado), fêmea, XI.1960, C. A. C. Seabra col. Magé, fêmea, 4.X.1989, L. Otero col. Santa Catarina: Corupá, macho, fêmea, 1940, A. Maller col. PARAGUAI, Neembucú: Jataity, fêmea, 23.I.1949, J. Miranda col. Todos no MNRJ.

Discussão. A pubescência cinzento-esbranquiçada que reveste o protórax pode ser densa e uniforme ou delimitar manchas castanho-escuras difusas nos lados do pronoto. Nos élitros as manchas longitudinais castanho-escuras estão nitidamente separadas no terço basal e na metade posterior ou podem se apresentar contínuas desde a base à extremidade elitral.

\section{Amniscites Gilmour, 1957}

Amniscites Gilmour, 1957: 4; Monné, 2005: 14 (cat.).

Espécie-tipo: Amniscus pictipes Bates, 1863 (por designação original).

Amniscites pertence ao grupo de gêneros com os seguintes caracteres: antenômeros III a XI lineares; élitros sem cerdas, sem carenas e com crista centro-basal; primeiro metatarsômero aproximadamente do mesmo comprimento que os dois seguintes em conjunto e últimos três urotergitos cobertos pelos élitros.

Compartilha com Alcathousites Gilmour, 1962 e Alcathousiella Monné, 2005 a presença nos machos de projeção espiniforme no lado interno da extremidade distal do antenômero III. Separa-se de Alcathousites Gilmour, 1962 pelo protórax com os lados arredondados, sem tubérculos e de Alcathousiella Monné, 2005 pelo escapo não dilatado na extremidade distal e sem projeção espiniforme no ápice. Distingue-se de Beloesthes Thomson, 1864 pelos élitros com uma crista centro-basal e de Erphaea Erichson, 1847 pelo processo mesosternal sem tubérculo. Em Alcathousites o protórax é tuberculado nos lados; em Alcathousiella o escapo é dilatado na extremidade distal e com projeção espiniforme na extremidade; em Beloesthes, além da crista centro-basal existem duas projeções espiniformes pós-medianas em cada élitro e em Erphaea o processo mesosternal apresenta tubérculo cônico.

\section{Chave para as espécies de Amniscites}

1. Tegumento predominante castanho-amarelado a castanhoalaranjado. (Fig. 7, 8). Costa Rica, Panamá, Equador e Bolívia ao Brasil (Amazonas, Pará, Espírito Santo e Rio de Janeiro) A. pictipes (Bates, 1863)

1'. Tegumento castanho-escuro a preto ............................ 2

2. Ápices dos élitros obliquamente truncados, com os ângulos apenas projetados; machos com primeiro protarsômero com projeção espiniforme lateral. (Fig. 9). Bolívia (Cochabamba, Santa Cruz) .................. A. amboroensis sp. nov.

2'. Ápices dos élitros arredondados; machos com protarsômero basal sem projeções (Fig. 10). Guiana Francesa A. tavakiliani sp. nov. 


\section{Amniscites pictipes (Bates, 1863)}

(Figs. 7, 8)

Amniscus pictipes Bates, 1863: 104.

Amniscites pictipes; Gilmour, 1957: 4; Wappes et al., 2006: 34 (distr.); Monné, 2005: 14 (cat.); Monné et al., 2010: 244 (distr.); Swift et al., 2010: 35 (distr.).

Espécie amplamente distribuída desde Costa Rica e Panamá, Equador e Bolívia ao Brasil (Amazonas, Pará, Espírito Santo e Rio de Janeiro).

\section{Amniscites amboroensis sp. nov.} (Fig. 9)

Etimologia. O nome específico refere-se a localidade de Amboro, uma das procedências do material examinado.

Macho. Tegumento predominante castanho-escuro; tegumento castanho-alaranjado nos três quartos basais dois antenômeros III-VII e na metade anterior dos seguintes, face ventral, coxas e fêmures (exceto mancha castanho-escura mediana). Pubescência predominante cinzento-esverdeada. A pubescência branco-amarelada recobre na cabeça mancha dorsal pós-ocular, no protórax, manchas arredondadas pequenas nos lados e junto à margem posterior, nos élitros estreita mancha oblíqua mediana, aproximada da sutura e distante da margem, anéis estreitos na base e no meio das tíbias e na metade anterior do primeiro metatarsômero.

As antenas atingem as extremidades dos élitros no ápice do antenômero VI; antenômero III com pequena projeção dentiforme no lado interno da extremidade distal. Lados do protórax arredondados, levemente estreitados nas margens anterior e posterior; pronoto com uma elevação obtusa a cada lado do meio na metade anterior. Superfície com pontos pequenos e esparsos no meio do disco, e uma fileira de pontos maiores junto às margens anterior e posterior. Processo prosternal com um terço da largura de uma procoxa; processo mesosternal metade da largura de uma mesocoxa. Ápices dos élitros obliquamente truncados, ambos os ângulos levemente projetados. Crista centro-basal pilosa, sem projeção do tegumento, formada por tufo denso de pelos pretos. Pontuação elitral fina e densa em toda a superfície. Último urotergito arredondado na extremidade distal; último urosternito truncado no ápice. Fêmures pedunculados, fortemente engrossados nos dois terços distais; primeiro protarsômero com projeção espiniforme lateral; primeiro metatarsômero uma vez e meia o comprimento dos dois seguintes em conjunto.

Fêmea. As antenas alcançam as extremidades dos élitros no ápice do antenômero VII; antenômero III sem projeção interna ápico-distal; primeiro protarsômero sem projeção espiniforme; último urotergito aguçado na extremidade; último urosternito truncado.

Dimensões, em mm, respectivamente macho/fêmea: Comprimento total, 5,8-6,5/6,0-6,5; comprimento do protórax, 1,0-1,3/1,1-1,2; comprimento dos élitros, 4,4-4,7/
4,5-4,9; maior largura do protórax, 1,6-1,8/1,4-1,7; largura umeral, 2,1-2,5/2,1-2,5.

Material-tipo. Holótipo macho, BOLÍVIA, Cochabamba: $69 \mathrm{~km}$ W Vila Tunari (600 m), 15.X.1992, E. Giesbert col. (MNKM). Parátipos: Santa Cruz: Road to Amboro, above Achira, 2 machos, 2 fêmeas, 10-15.X.2006, Wappes, Nearns \& Eya col. (macho e fêmea no ACMT e MNRJ). Chaco above Achira (1730 m), fêmea, 22-25.I.2007, Wappes \& Lingafelter col. (ACMT). Refúgio Los Volcanes (1045 m), macho, 18-21.I.2006, Wappes \& Lingafelter col. (ACMT).

\section{Amniscites tavakiliani sp. nov.}

(Fig. 10)

Etimologia. O nome homenageia o Dr. Gerard Luc Tavakilian (MNHN), por sua valiosa contribuição ao conhecimento da família Cerambycidae.

Macho. Tegumento castanho-escuro a preto. Três quartos anteriores dos antenômeros II-IV e metade basal dos seguintes com tegumento castanho-avermelhado. Pubescência predominante castanho-escura. A pubescência branca recobre o terço anterior dos lados do pronoto e a metade anterior dos lados do protórax; nos élitros uma pequena mácula arredondada central apenas pós-mediana. Pubescência castanho-amarelada reveste com abundantes manchas pequenas e irregulares os lados do pronoto e dos élitros, mais densas na metade distal dos mesmos. Fêmures revestidos com pubescência acinzentada, exceto mancha dorsodistal castanho escuro; tíbias castanho- escuras, com anel mediano acinzentado.

As antenas alcançam as extremidades dos élitros no ápice do antenômero V; antenômero III com pequena projeção dentiforme no lado interno da extremidade distal. Lados do protórax arredondados e estreitados no terço posterior. Pronoto com elevação obtusa a cada lado do meio, junto à margem anterior. Superfície com pontos pequenos e esparsos no meio do disco, uma fileira junto à margem anterior e duas fileiras junto a margem posterior. Processo prosternal muito estreito, um décimo da largura de uma procoxa; processo mesosternal com cerca de um quarto da largura de uma mesocoxa.

Ápices dos élitros arredondados; crista centro-basal formada por curto tufo de pelos pretos, sem projeções do tegumento; pontuação elitral fina, densa e uniformemente distribuída em toda a superfície. Últimos urotergito e urosternito transversalmente truncados. Mesofêmures engrossados para a extremidade; metafêmures menos engrossados. Primeiro metatarsômero com a metade basal castanho-clara, apenas mais longo que os dois seguintes em conjunto.

Fêmea. Antenômero III sem projeção dentiforme. Últimos urotergito e urosternito arredondados na extremidade distal.

Dimensões, em mm, respectivamente macho/fêmea: Comprimento total, 4,7-5,3/4,8-5,2; comprimento do protórax, 1,2-1,3/1,0-1,1; comprimento dos élitros, 3,0-3,5/ $3,2-3,5$; maior largura do protórax, 1,5-1,6/1,4-1,6; largura umeral, 1,8-2,0/1,9-2,0. 

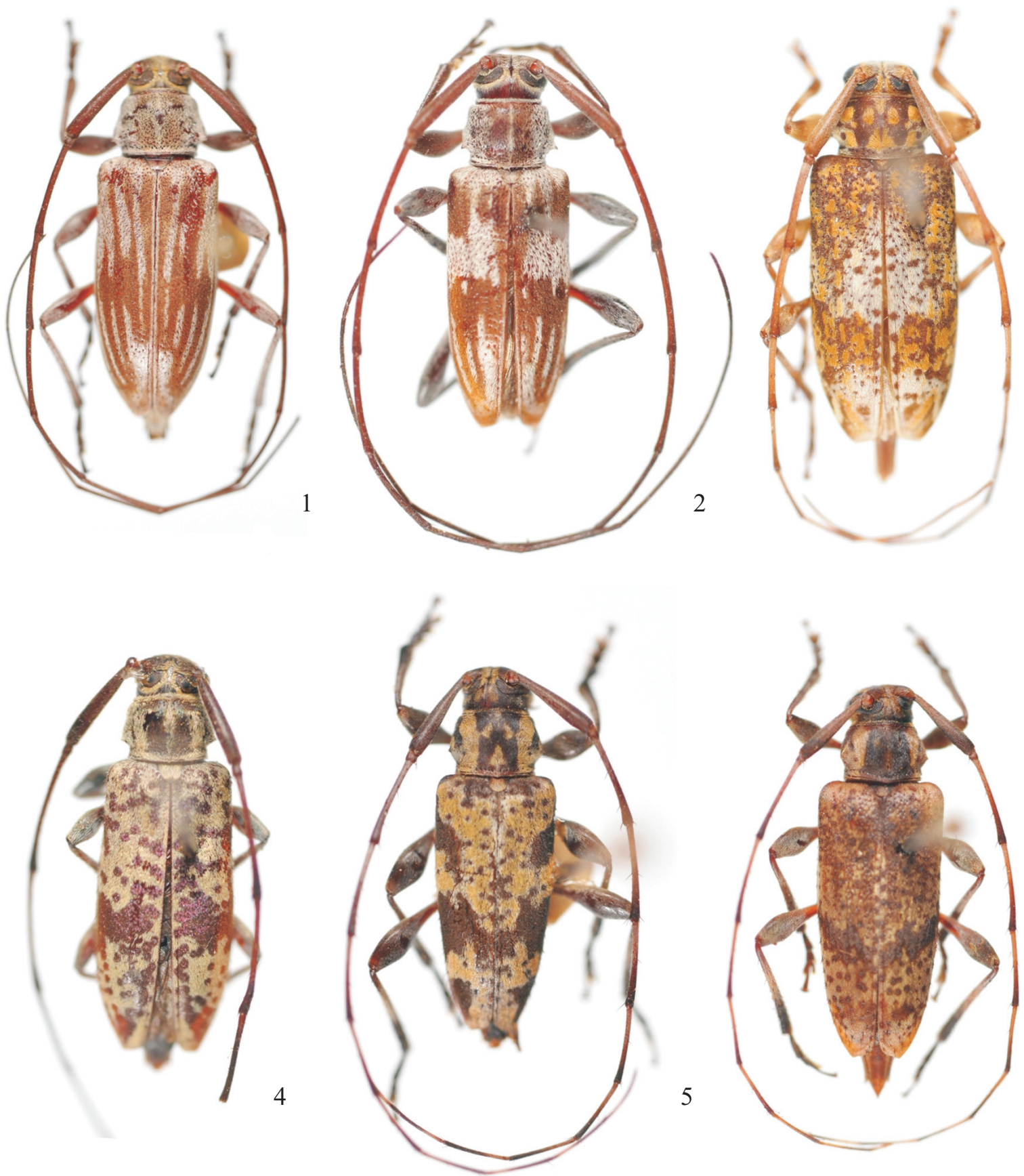

Figs. 1-6. 1. Trichonyssodrys nessimiani sp. nov., parátipo fêmea; 2. T. nessimiani sp. nov., parátipo macho; 3. T. aureopilosus Monné, parátipo fêmea; 4. T. maculatus Gilmour, fêmea; 5. T. melasmus Delfino, parátipo macho; 6. T. cinctus Delfino, parátipo fêmea.

Material-tipo. Holótipo macho, GUIANA FRANCESA, Route de Kaw, pk 34, 13.II.1983, G. Tavakilian col. "piégeage lumineux" (ex-collection IRD, MNHN). Parátipos: Mesmos dados do holótipo, fêmea, 20.III.1983 (MNHN); mesma localidade, pk 35, fêmea, 11.VI.1983, C. Feuillet col. (MNRJ), pk 40, macho. 21.VII.1984 (MNHN), fêmea, 05.II.1986. F. \& J.-P. Serais col. (MNRJ), fêmea, 24.II.1993, J. Cerda col. (MNHN). Piste Forestière de Saut Léodate, fêmea, 04.II.1997 M. Thouvenot col. (MNHN). Piste des Compagnons Réunis, pk 27, macho, 25.I.1987, M. Duranton col. (MNHN), mesmos dados, macho, 21.VIII.1987 (MNHN), macho, 12.XII.1987, (MNRJ). Route Nationale 2, macho, 28.I.1990, M. Vialard col. (MNHN). Piste de la Montagne de Fer, pk 18, macho, 17.VIII.1988, R. Garrouste col. (MNRJ), mesmos dados, fêmea, 15.IX.1989 (MNHN). Piste des Eaux Claires, macho,
2.XII.1987, M. Duranton col; (MNRJ). Piste du plateau des Mines, pk 6, macho, 06.II.1986, B. \& J. Lalanne-Cassou col. (MNHN). Crique Nancibo, macho, fêmea, II.1983, M. Duranton col. (MNRJ). Piste du plateau de Nancibo, pk 2, macho, 22.II.1983, G. Corn col. (MNHN).

Discussão. Amniscites tavakiliani sp. nov. difere de $A$. pictipes por detalhes da coloração do tegumento e da pubescência, castanho-escuros a pretos, em $A$. pictipes ambas são castanho-avermelhados ou castanho-alaranjados, ainda nesta espécie o pronoto apresenta duas linhas longitudinais de pubescência preta, ausentes em $A$. tavakiliani sp. nov. 

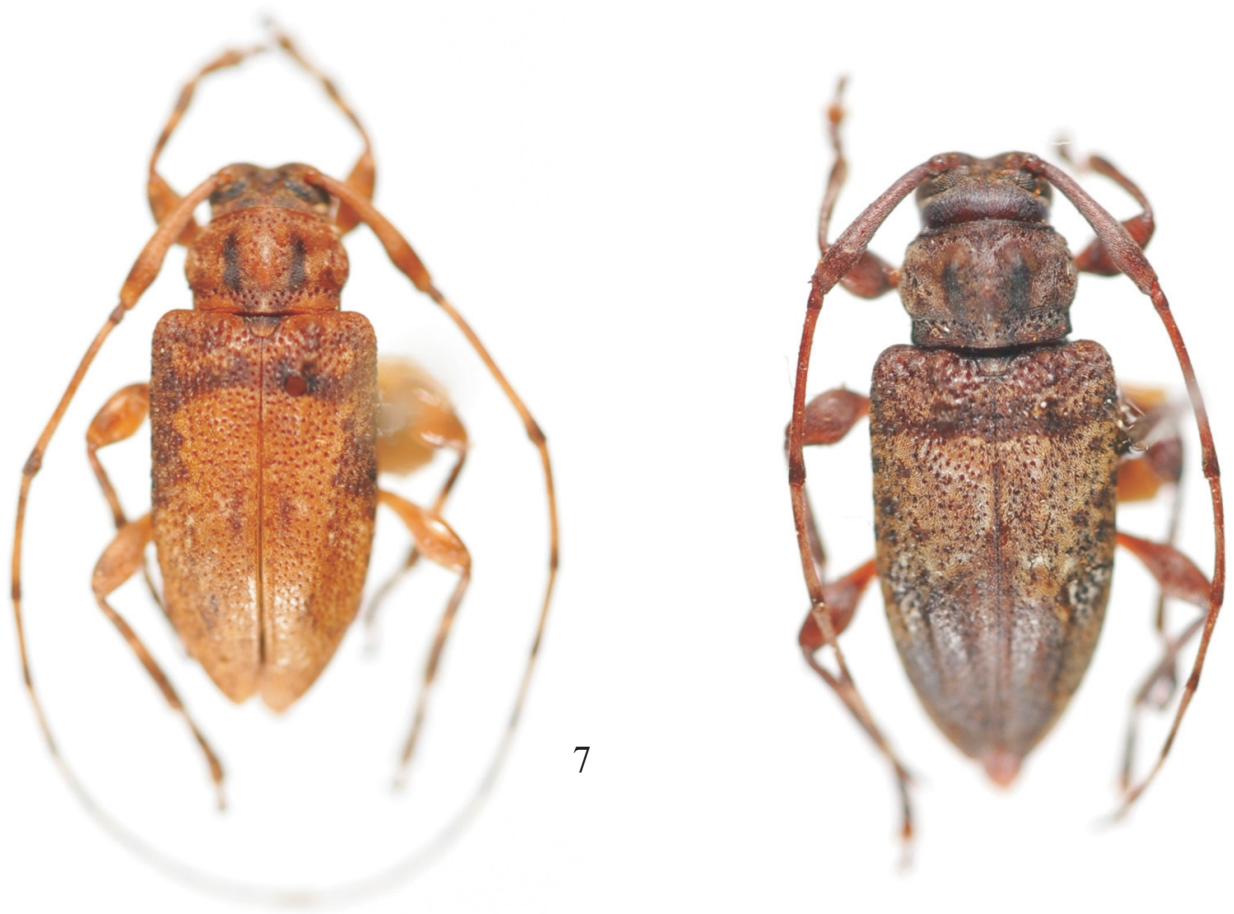

8
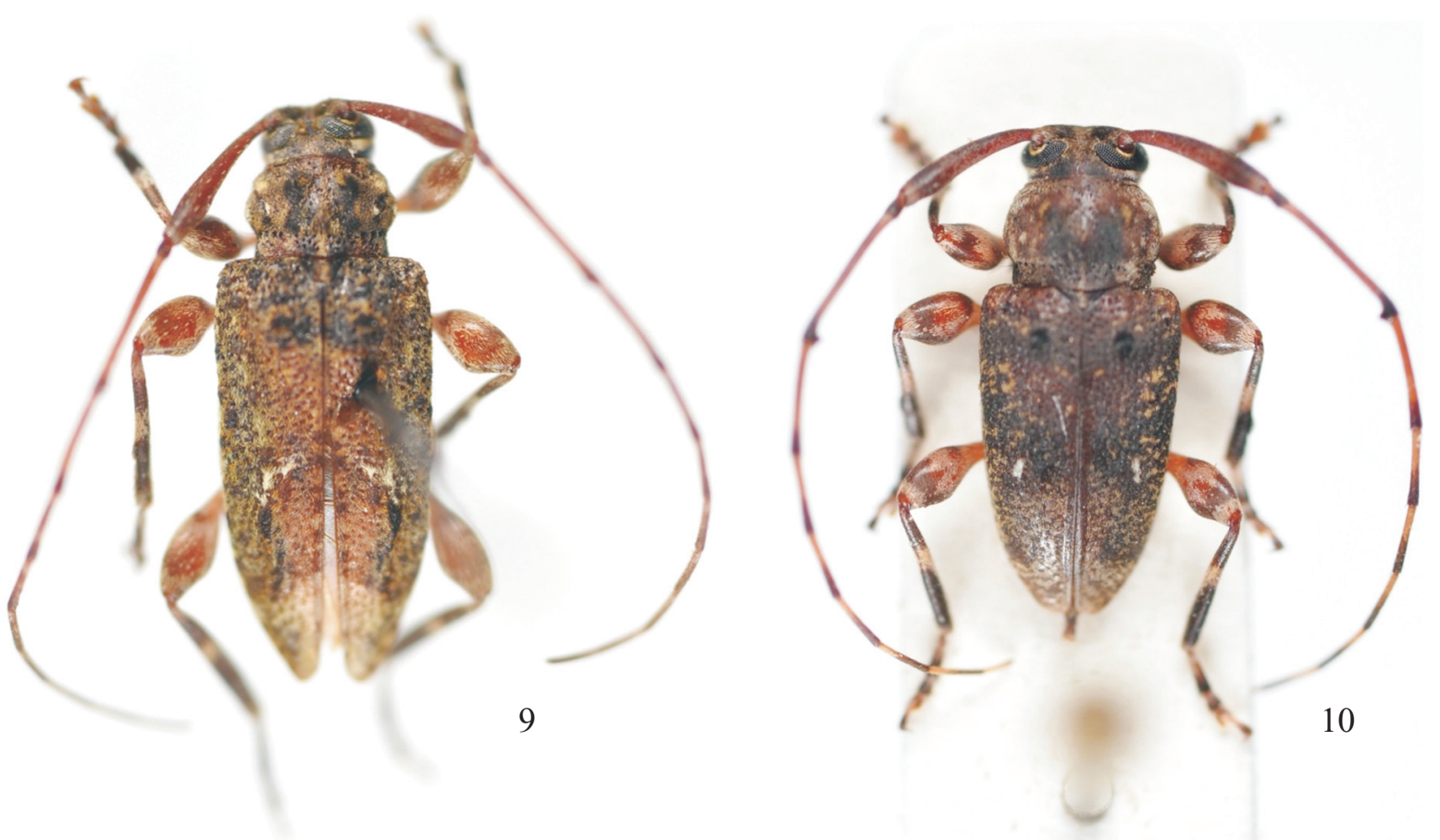

Figs. 7-10. 7, 8. Amniscites pictipes (Bates), fêmea; 9. A. amboroensis sp. nov., holótipo macho; 10. A. tavakiliani sp. nov., holótipo macho.

\section{Luteolepturges gen. nov.}

Etimologia. Latim, luteo significa amarelo + Lepturges gênero de Acanthocinini.

Corpo achatado dorsoventralmente. Élitros sem cerdas, sem crista centro-basal e sem carenas. Olhos grosseiramente facetados, lobos superiores tão afastados entre si quanto três vezes e meia a largura de um lobo; lobos inferiores pelo menos duas vezes a altura das genas. Antenas com 11 antenômeros, apenas ultrapassam as extremidades dos élitros; escapo levemente engrossado no ápice distal; antenômeros III-XI decrescentes para a extremidade. Protórax com tubérculo lateral proeminente no início do terço posterior, o ápice aguçado e dirigido para os lados. Pronoto sem tubérculos com depressão rasa centro-mediana, limitada lateralmente por área levemente elevada. Processo prosternal com largura igual a 
um quinto da largura de uma procoxa; processo mesosternal um terço da largura de uma mesocoxa. Escutelo arredondado no ápice, revestido de densa pubescência. Élitros planos nos três quartos anteriores junto da sutura, com suave declive para a margem lateral e para as extremidades. Ápices dos élitros arredondados. Pernas curtas, fêmures e tíbias sublineares; primeiro metatarsômero ligeiramente mais curto que os dois seguintes em conjunto.

Espécie-tipo: Luteolepturges galbus sp. nov.

Discussão. Pelos élitros sem cerdas eretas, sem carenas e sem crista centro-basal, pelo pronoto sem tubérculos e pela presença de tubérculo lateral manifesto no protórax assemelha-se a Lepturges Bates, 1863 e Lepturgantes Gilmour,1957, difere de ambos pelas antenas, aproximadamente do comprimento do corpo em Luteolepturges e pelo menos duas vezes maiores que o corpo em Lepturges e Lepturgantes, além disso nestes dois gêneros os élitros são pontuados em toda a superfície e os tubérculos laterais do protórax são coincidentes com os ângulos posteriores, em Luteolepturges a pontuação esta restrita a uma área longitudinal estreita da base até o inicio do terço distal, e os tubérculos laterais do protórax estão localizados no início do terço posterior. A coloração amarelo-acastanhada e a forma do corpo deprimida dorsoventralmente são caracteres em comum com Neseuterpia Villiers, 1980, contudo neste gênero o protórax apresenta tubérculos medianos e é estreitado anterior e posteriormente e os machos possuem fêmures pedunculado-clavados e protíbias curvas. Em Luteolepturges os lados do protórax são regularmente divergentes até a extremidade dos tubérculos e posteriormente apenas estreitados, os fêmures são lineares e as protíbias sem modificações.

\section{Luteolepturges galbus sp. nov.}

(Figs. 11, 12)

Etimologia. Latin, galbus, amarelado, referente à coloração predominante castanho-amarelada.

Macho. Tegumento de maneira geral castanho-amarelado, castanho-escuro na cabeça, escapo e protórax. Élitros com mancha linear castanho-escura numa depressão longitudinal do meio da base até o início de quarto apical. As antenas alcançam as extremidades elitrais no ápice do antenômero $\mathrm{X}$; antenômero XI do mesmo comprimento que o X, levemente estreitado na metade distal. Pronoto muito fina e densamente pontuado em toda a superfície; sem fileira de pontos junto bordas anterior e posterior. Élitros com os ápices arredondados; pontuação fina e esparsa, restrita à área deprimida castanho-escura. Superfície ventral fina e densamente revestida de pubescência amarelada e pelos longos esparsos nos urosternitos distais. Último urotergito triangularmente emarginado na extremidade; último urosternito transversalmente truncado.

Fêmea. As antenas apenas alcançam as extremidades dos élitros; último urotergito projetado cerca de $0,5 \mathrm{~mm}$ além dos ápices dos élitros com a extremidade distal semicircularmente entalhada; último urosternito transversalmente truncado.
Dimensões, em mm, respectivamente macho/fêmea: Comprimento total, 8,0/7,0-8,5; comprimento do protórax, 1,4/1,2-1,6; comprimento dos élitros, 5,9/5,0-6,2; maior largura do protórax, 2,2/2,0-2,6; largura umeral, 3,0/2,6-3,2.

Material tipo, holótipo macho: BRASIL, Rondônia: Rio Madeira, Mutum-Paraná, 19.XI.2003, M.A.R.A. Silveira col. (MNRJ). Parátipos: BRASIL, Amazonas: Benjamin Constant, fêmea, VIII.1960, Dirings. col. (MZSP). EQUADOR, Coca, 3 fêmeas, V.1984, G. Onore col. (MNRJ). PERU, Loreto: Pucallpa, fêmea, 26.I.1963, J. M. Schunke col. (MNRJ).

\section{Trichonius Bates, 1864}

Trichonius Bates, 1864: 52; Monné, 2005: 140 (cat.); Monné \& Mermudes, 2008: 7 (rev.).

Espécie-tipo: Trichonius quadrivittatus Bates, 1864, designação de Thomson, 1864.

O gênero Trichonius recentemente revisto por Monné \& Mermudes (2008), engloba hoje 8 espécies, sete das quais com distribuição amazônica e apenas uma, Trichonius atlanticus Monné \& Mermudes, 2008, distribuída na Mata Atlântica. Descrevemos a seguir a segunda espécie com distribuição meridional.

\section{Trichonius inusitatus sp. nov.}

(Fig. 13)

Etimologia. Latin, inusitatus: estranho, incomum, invulgar, referente à distribuição meridional da espécie nova.

Fêmea. Tegumento castanho-escuro a preto. Cabeça com pubescência preta, com mancha de pubescência castanhoamarelada entre os tubérculos anteníferos. Metade ou terço anterior dos antenômeros III-XI revestidos com pubescência acinzentada. Protórax revestido com pubescência preta, ápices dos tubérculos laterais e quatro máculas arredondadas na metade anterior do pronoto cobertas com pubescência amarelo-esbranquiçada. Metade anterior dos élitros predominantemente castanho-amarelada, metade posterior com predominancia de pubescênca preta, as duas cores predominantes separadas por faixa transversal irregular cinzentoesbranquiçada apenas pós mediana, que se prolonga ao longo da sutura na metade basal; extremo ápice dos élitros com mácula castanho-amarelada.

As antenas ultrapassam os ápices dos élitros na extremidade distal do antenômero VI; antenômeros III-XI com cerdas longas muito esparsas em toda a superfície. Lados do protórax com projeção aguçada no início do terço posterior; pronoto com fileira transversal de pontos junto a borda posterior. Processo prosternal cerca da metade da largura da procoxa; processo mesosternal subigual à largura da mesocoxa. Élitros com os ápices obliquamente truncados, ângulos sem projeções. Superfície com pontos esparsos na metade anterior. Fêmures sem cerdas, meso- e metatíbias com cerdas longas, moderadamente esparsas. Último urotergito triangular, truncado na extremidade distal; último urosternito truncado. 

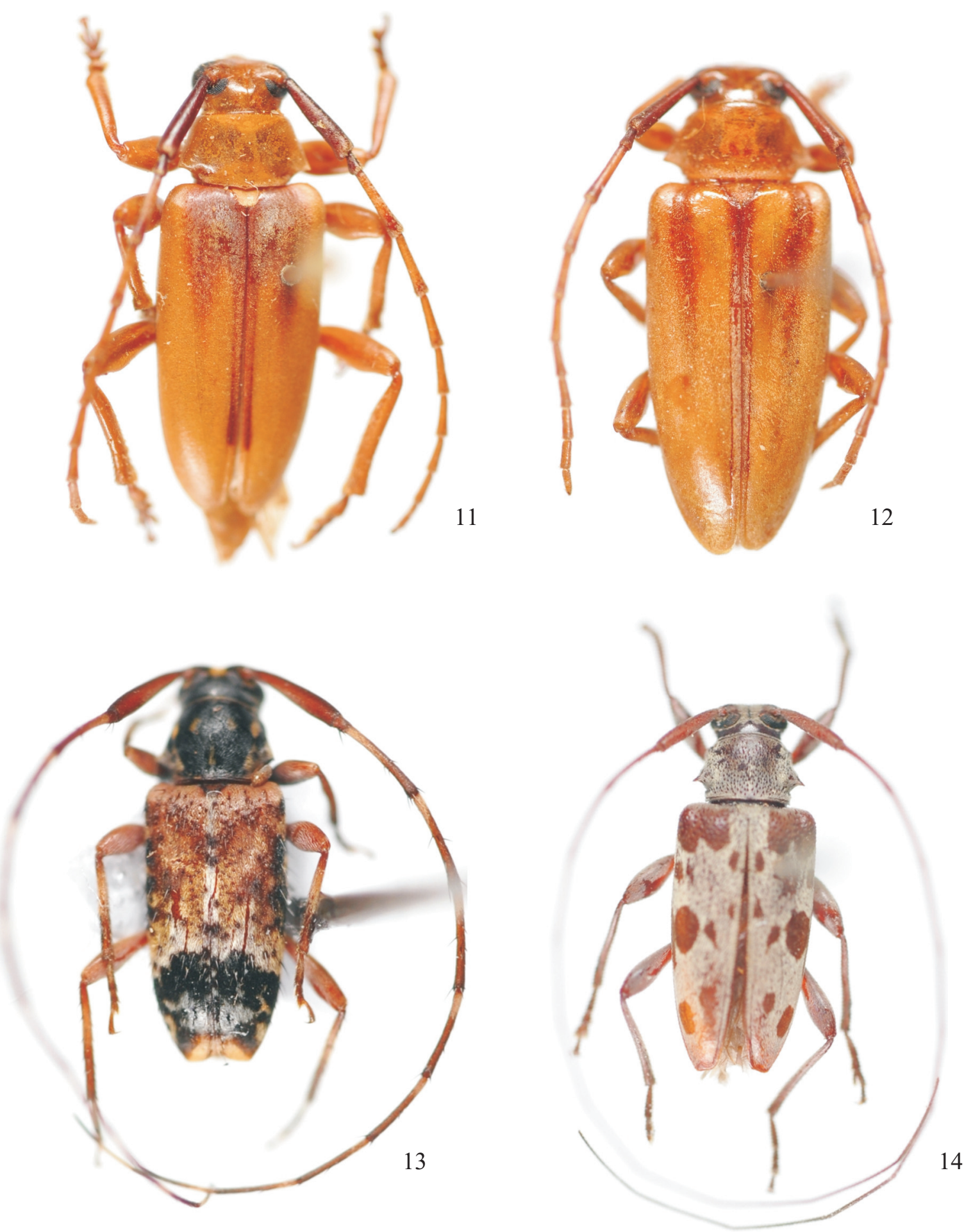

Figs. 11-14. 11. Luteolepturges galbus sp. nov., holótipo macho;12. L. galbus sp. nov., parátipo fêmea; 13. Trichonius inusitatus sp. nov., holótipo fêmea; 14. Lophopoenopsis itatiaiensis sp. nov., holótipo fêmea.

Macho. As antenas alcançam os ápices dos élitros na extremidade distal do antenômero $\mathrm{V}$; últimos urotergito e urosternito transversalmente truncados no ápice.

Dimensões, em mm, respectivamente macho/fêmea: Comprimento total, 4,9-7,0/5,2-7,3; comprimento do protórax, 1,0-1,3/1,1-1,5; comprimento dos élitros, 3,2-5,0/
3,6-5,0; maior largura do protórax, 1,3-2,3/1,4-2,0; largura umeral, 1,5-2,6/1,8-2,5.

Material-tipo. Holótipo fêmea, BRASIL, Rio de Janeiro: Parque Nacional do Itatiaia, 750 m, 23.IX.2011. M. L. \& M. A. Monné col. (MNRJ). Parátipos: Bahia: Mun. Encruzilhada (Estrada Rio-Bahia, km 965, 960 m), fêmea, XI.1972, Seabra \& Roppa col. Minas Gerais: Poços de Caldas, fê- 
mea, XII.1976, M. A. Monné col. São Paulo: São Paulo (Jabaquara), macho, XII.1941, H. Zellibor col.; mesmo local e coletor, macho, fêmea, $7-$ 14.I.1944. Marília, macho, 1.XI.1947, H. Zellibor col. Santa Catarina: Seara (Nova Teutonia), 4 machos, 3-10.X.1941, F. Plaumann col., mesmo local e coletor, macho, 31.X.1941; macho, 2 fêmeas, 6.XII.1941, 3 machos, fêmea, X.1973. Todos no MNRJ.

Discussão. Trichonius inusitatus sp. nov., difere de $T$. atlanticus Monné \& Mermudes, 2008, pela coloração da pubescência e pelo desenho do pronoto e élitros. Em $T$. atlanticus predomina nos élitros a pubescência cinzento-esbranquiçada e em T. inusitatus sp. nov. as pubescências elitrais predominantes são castanho-amarelada e preta.

\section{Lophopoenopsis Melzer, 1931}

Lophopoeum (Lophopoenopsis) Melzer, 1931: 63.

Lophopoenopsis; Monné \& Monné, 2007: 1041.

O gênero foi revisto recentemente por Monné \& Monné (2007), descrevemos a terceira espécie.

\section{Lophopoenopsis itatiaiensis sp. nov.}

(Fig. 14)

Etimologia: O epíteto faz referência ao Parque Nacional do Itatiaia, local de coleta do holótipo.

Fêmea. Tegumento castanho-escuro, revestido predominantemente por pubescência cinzento-esbranquiçada, mais densa nos lados do pronoto e nos élitros. A pubescência castanho-escura recobre mancha umeral posteriormente bilobada, duas pequenas máculas subarredondadas no terço anterior de cada élitro, uma aproximada da sutura e a outra da margem, mancha arredondada mediana, aproximada da margem, duas manchas pequenas próximas à sutura e três pequenas máculas no terço distal.

Antenas longas atingem a extremidade dos élitros na extremidade distal do antenômero VI. Tubérculos laterais do protórax situados no início do terço posterior, aguçados e proeminentes, a extremidade ligeiramente dirigida para trás. Pronoto fina e densamente pontuado em toda a superfície. Élitros com os ápices transversalmente truncados, ângulos não projetados. Metade anterior com pontos pequenos, moderadamente densos, mais esparsos na metade distal. Processo prosternal com um quinto da largura de uma procoxa; processo mesosternal com cerca de um quarto da largura de uma mesocoxa. Último urotergito truncado, com ligeiro entalhe mediano na extremidade distal; último urosternito semicircularmente entalhado, ângulos projetados em espinhos aguçados.

Dimensões, em mm, holótipo fêmea: Comprimento total, 6,6; comprimento do protórax, 1,4; comprimento dos élitros, 4,9; maior largura do protórax, 2,0; largura umeral, 2,4.
Material-tipo. Holótipo fềmea, BRASIL, Rio de Janeiro: Parque Nacional do Itatiaia, 700 m, 20-28.XI.1968, H. S. \& M. A. Monné col. (MNRJ).

Discussão. L. itatiaiensis sp. nov. separa-se de L. albosparsus Monné \& Monné, 2007, pelos lobos superiores dos olhos tão distantes entre si quanto a largura de um lobo, em $L$. albosparsus são aproximados, distantes entre si $1 / 4$ da largura de um lobo, além disso separam-se pelo desenho e pela cor predominante da pubêscencia elitral, em L. itatiaiensis é branco-acinzentada e em L. albosparsus a pubescência dessa cor recobre apenas faixa transversal mediana de contornos irregulares e mancha anteapical em forma de "U". Em L. singularis Melzer, 1931 a mancha cobre os dois terços distais dos élitros, ao longo da sutura, expandida no terço mediano e no terço distal.

\section{AGRADECIMENTOS}

Agradecemos aos colegas James Wappes (ACMT) e Gerard Luc Tavakilian (MNHN) pelo envio de material para estudo.

\section{REFERENCIAS}

Bates, H. W., 1863. Contributions to an insect fauna of the Amazon Valley. Coleoptera: Longicornes The Annals and Magazine of Natural History 12: 100-109.

Bates, H. W. 1864. Contributions to an insect fauna of the Amazon Valley. Coleoptera: Longicornes The Annals and Magazine of Natural History 13: 43-56

Delfino, S. M., 1981. Revisão do gênero Trichonyssodrys Gilmour, 1957 (Coleoptera, Cerambycidae, Lamiinae, Acanthocinini). Revista Brasileira de Biologia 41: 255-258.

Gilmour, E. F., 1957. On the Neotropical Acanthocinini (Coleoptera, Cerambycidae, Lamiinae). Some new genera and species. Arquivos de Biologia e Tecnologia, 10: 3-36.

Melzer, J., 1931. Longicórneos americanos, principalmente do Brasil, novos ou pouco conhecidos (Coleoptera, Cerambycidae). Archivos do Instituto Biológico 4: 51-82.

Monné, M. A. 2005. Catalogue of the Cerambycidae (Coleoptera) of the Neotropical Region. Part II. Subfamily Lamiinae. Zootaxa 1023: 1759.

Monné, M. A. \& M. L. Monné. 2007. Novas espécies neotropicais de Acanthocinini (Coleoptera, Cerambycidae). Revista Brasileira de Zoologia 24: 1038-1042.

Monné, M. L.; M. A. Monné; R. S. Martins; M. V. dos P. Simões \& V. S. Machado, 2010. Espécies de Cerambycidae (Insecta, Coleoptera) ocorrentes no Estado do Rio de Janeiro (Brasil). Arquivos do Museu Nacional 67: 235-251.

Monné, M. L. \& J. R. M. Mermudes, 2008. Revisão de Trichonius Bates (Coleoptera, Cerambycidae, Lamiinae). Revista Brasileira de Entomologia 52: 7-12.

Swift, I. P.; L. G. Bezark; E. H. Nearns; A. Solís \& F. T. Hovore. 2010. Checklist of the Cerambycidae (Coleoptera) of Costa Rica. Insecta Mundi 131: 1-68.

Wappes, J. E.; R. F. Morris II; E. H. Nearns \& M. C. Thomas, 2006. Preliminary list of Bolivian Cerambycidae (Coleoptera). Insecta Mundi 20: $1-45$. 